\title{
INTRODUCCIÓN AL ESTUDIO DEL TEATRO ESPAÑOL UNIVERSITARIO EN SU PRIMERA ETAPA (1940-1951): UNA BIBLIOGRAFÍA CRÍTICA
}

\author{
JaVier Huerta CALVO \\ Instituto del Teatro de Madrid-UCM
}

\section{En los orígenes del TEU}

La escena española de posguerra es inexplicable sin la compleja y dilatada experiencia del Teatro Español Universitario (TEU). A pesar de esta poco cuestionable afirmación, la historiografía teatral ha sido en exceso cicatera con el fenómeno del TEU, sobre todo en su periodo inicial, de 1940 a 1951. Es muy probable que, en esa desatención, haya tenido mucho que ver la «teoría del erial», es decir, la corriente de opinión según la cual nada digno produjo la cultura del franquismo, sobre todo si se la compara con la ocurrida durante los años anteriores a la Guerra Civil, es decir, la etapa republicana, a la que se contempla por regla general desde una perspectiva más idealizadora que realista, como si fuera la culminación de la llamada Edad de Plata, cuyos hitos se dieron preferentemente en el periodo anterior. Un examen desapasionado demuestra que, al menos en lo que al teatro se refiere, ni la situación republicana fue tan extraordinaria como se dice, ni la posterior a la guerra tan absolutamente negativa. Es cierto que, en cuanto a los autores, no hay un nombre de la talla de Federico García Lorca hasta al menos la irrupción de Antonio Buero Vallejo en 1949, pero en otros sectores de la vida escénica el balance dista mucho de ser tan catastrófico como se suele pintar. Si el teatro republicano tuvo en Cipriano Rivas Cherif su gran animador y el primer gran director de escena propiamente dicho (Aguilera / Aznar Soler, 1999), la franquista -limitándonos a la década de los 40- tuvo tres dignísimos continuadores suyos en el malogrado Felipe 
Lluch, Cayetano Luca de Tena y Luis Escobar, cuyas aportaciones han sido convenientemente subrayadas por estudiosos como Víctor García Ruiz (2010), Blanca Baltés (2011) y Juan Aguilera Sastre (2001), respectivamente. Y algo similar podría decirse respecto a otros ámbitos de la vida escénica como la escenografía y el figurinismo y, sobre todo, la interpretación. El TEU fue un incesante vivero de artistas, como ha escrito Mario Antolín:

El TEU cumplió una misión importantísima en todos los distritos universitarios de España: llevó el Teatro a la Universidad y la Universidad al Teatro. Dio a la escena española primerísimas figuras como María Jesús Valdés, María Fernanda d'Ocón, Berta Riaza, José María Rodero, [Adolfo] Marsillach, José María Prada, Juanjo Menéndez y tantos otros directores como José Tamayo, Alberto González Vergel, Juan Antonio Hormigón, César Oliva, [Ángel] Fernández Montesinos, Modesto Higueras, Gustavo Pérez Puig, Salvador Salazar, etc. Sin nuestros errores, sin nuestras audacias, sin nuestros sueños, estoy seguro de que el teatro en España no hubiera alcanzado el alto nivel que posee (Antolín, 2000: 177).

Así pues, a pesar de los pesares -y estos pesares fueron desde luego tan indignos como lamentables-, la praxis escénica de la posguerra no supuso un corte radical con la anterior a la Guerra Civil. «Algunos de estos nombres -ha escrito César Oliva refiriéndose a los anteriormente enunciados y a otros más- están muy vinculados a proyectos republicanos, lo que no deja de ser significativo, no tanto por su paradoja ideológica como por la evidencia de que, salvo en el terreno de la autoría teatral, el tránsito de la profesión de la izquierda a la derecha se produjo con mucha más normalidad de la que cabía esperar» (1999). Justamente, el Teatro Español Universitario (TEU) es un buen ejemplo de ese tránsito relativamente normal entre dos circunstancias políticamente tan antagónicas. Para uno de los mejores historiadores de la cultura de posguerra, Jordi Gracia, resulta «de especial significado la explícita vinculación que enlaza La Barraca o las Misiones Pedagógicas con iniciativas como el Teatro Popular Universitario, el SEU, el Servicio Universitario del Trabajo (SUT) y, en general, el ansiado acercamiento entre obreros e intelectuales como lema de una vanguardia intelectual», aunque a continuación matiza: «procedía del fracaso de quienes habían sostenido la misma ilusión en los medios radicales de Falange, las reservas del SEU y la gestación originaria del Teatro Español Universitario (TEU)» (Gracia, 2006: 32).

Es esta una impresión que ya se tenía por aquellos años. En 1940, por ejemplo, un anónimo redactor del semanario España popular, afirmaba desde el exilio:

El Estado falangista quiere imitar a la República en algunas cosas. Pero, naturalmente, se le frustran los propósitos, y no hace falta decir por qué. Hace 
unos días comentábamos la Fiesta del Libro que Franco ha querido instituir a la manera republicana. Hoy nos llegan noticias del Teatro Universitario que el Sindicato de Estudiantes [se refiere al SEU] ha fundado, sin duda, para imitar aquel otro de La Barraca que creó la República y que dirigía García Lorca. Naturalmente, este teatro está integrado por señoritos de la Falange que se dedican a recorrer las provincias representando El divino impaciente de Pemán y otros esperpentos por el estilo, y a organizar mítines de carácter fascista (Anónimo, 1940).

Las analogías eran palmarias. El Sindicato Español Universitario (SEU), único luego de la victoria, había sido en los años 30 la respuesta del partido falangista a la mítica Federación Universitaria Escolar (FUE), vinculada a las ideas institucionistas y republicanas. En el seno de la FUE había surgido, en el otoño de 1931, la idea de crear un Teatro Universitario, denominado en seguida La Barraca por el que fuera su director y alma máter, Federico García Lorca (Byrd, 1975; Sáenz de la Calzada, 1976; Huerta Calvo, 2011, 2012). Al fundarse el SEU, no fueron pocos los estudiantes de la FUE que se pasaron al nuevo sindicato. Algunos de ellos habían formado parte incluso de La Barraca. El caso más llamativo es el de Eduardo Ródenas Llusiá, actor en las primeras funciones del grupo y luego crítico teatral de Haz, el órgano de Falange Española. En otro lugar he examinado las reseñas críticas de este «barraco» falangista que sería asesinado a los pocos días del golpe de estado del 18 de julio. En 1935, Ródenas guardaba todavía un agradecido recuerdo a La Barraca, pues atacaba al gobierno de la CEDA por su política restrictiva respecto a las subvenciones recibidas por la compañía universitaria:

Mañana a otro pueblo, a un nuevo lugar: las mismas caras, los mismos tipos; un rincón de España más que recibe una, dos, tres horas de alegría. ¿Merece la pena? Nuestras cerriles derechas dicen que no. Nosotros decimos claramente que sí (Ródenas Llusiá, 1935).

Esta favorable impresión de Ródenas sobre La Barraca era compartida por otros camaradas suyos, que encontraban encomiable, por popular y antiburguesa, la misión cultural del grupo de Lorca. El luego célebre novelista Rafael García Serrano es uno de los más explícitos al respecto. Otros, aun compartiendo los objetivos esenciales de un teatro de vocación revolucionaria, se desmarcaban de la línea ideológica que señalaba el repertorio de La Barraca, como este anónimo articulista convertido en fanático proselitista:

Teatro universitario. Teatro de estudiantes. Obra joven que lleva por los pueblos y aldeas el rancio sabor de nuestro teatro clásico, Los estudiantes del SEU te saludan y te desean albricias en la obra de renovación cultural que te está encomendada.

Que te está encomendada, pero que no cumples. 
Estudiantes de La Barraca; vosotros habéis de llevar a lo más profundo del pueblo la cultura y el bienestar del espíritu. Vuestro deber ante ese pueblo hambriento que os escucha es darle un ejemplo de sacrificio. Un ejemplo de sacrificio estudiantil, no un ejemplo de libertinaje y de derroche de un dinero que no es tuyo, que pertenece enteramente al pueblo que te escucha. [...] El SEU te llama a sus filas; a ti y a La Barraca. A ti, como joven; a La Barraca, como misión pedagógica que ha de ser conducida tan solo por los que ansíen una Patria nueva; los que laboran por un porvenir de Imperio; no por los que se mueven en las aguas turbias y cenagosas de un marxismo judío (Anónimo, 1934).

Salvo la extemporánea y rastrera alusión antisemita, con las invocaciones al pasado imperial de la raza, el párrafo acredita que los falangistas admiraban La Barraca más por su continente e intención que por su contenido y logros alcanzados, tras los cualez se veía la sedicente mano del laicismo republicano y del marxismo, causantes según ellos de la guerra, como se denunciaría en años posteriores:

Aquellos politiquillos del Frente Popular crearon la agrupación artística titulada La Barraca, a la que solo podían pertenecer aquellos estudiantes universitarios que militasen en la FUE, puesto que era un feudo exclusivamente suyo. Y allá iba La Barraca, envenenando con su literatura morbosa las aldeas y los pueblos de España, para desatarlos después en el odio y el fratricidio inhumano y desgarrador que tan funestas consecuencias ha traído para todos (Toledano, 1937).

Otro falangista histórico, David Jato, ofrece el testimonio de la admiración que, con todas las reservas que se quieran tenían los seuístas hacia La Barraca:

Algo típicamente universitario veía escapar el SEU. Se trataba del teatro de estudiantes, La Barraca farandulera que en las manos de la FUE recorría con su acento desenvuelto los pueblos de la Patria (1953: 112-113).

Así es que con la victoria los falangistas iban a tener la oportunidad de imitar un modelo de teatro que, en el fondo, compartían y hasta envidiaban. Ya desde los primeros momentos de la guerra, la Falange consideró que el teatro debía ocupar un lugar relevante en la acción propagandística del nuevo régimen. Aunque el primer estreno oficial del TEU no se produjera hasta 1940, desde 1937 se habla de la necesidad de crear un teatro falangista o nacional-sindicalista. En el otoño de 1936 surge en Huelva el que será el germen del TEU: La Tarumba (Anónimo, 1936, 1937a, 1937b, 1937c, 1938a; Clavería, 1937; Escobar, 1938, 2000; Dennis / Peral, 2010). La Tarumba fue una simple agrupación provincial primero, que en seguida pasó a llamarse «teatro universitario de Falange». El nombre, calcado de otro proyecto teatral republicano, del que fuera responsable el pintor Miguel Prieto, era otro guiño a Lorca y La Barraca 
(VV.AA, 2007). Entre los fundadores de esta nueva Tarumba estaban Manuel de la Corte, como director (más tarde lo sería Augusto García Viñolas), los hermanos Orta Manzano, el músico Emilio Molero Monís, los poetas Rafael Manzano y Jesús Arcensio y el pintor José Caballero, este último gran amigo de Lorca y escenógrafo de La Barraca, con unos decorados magníficos para El caballero de Olmedo (Cienfuegos / Huerta Calvo, 2014). Como escribía un crítico entusiasta cuando vio actuar al grupo en Cádiz, La Tarumba cumplía la alta misión de «ir creando un espíritu revolucionario, un nuevo modo de ver y sentir a tono con la nueva mentalidad creada por la guerra; un modo espiritualmente revolucionario de hacer Patria, de preparar las mentes para cuando vuelvan victoriosas las banderas» (Cl.A, 1937: 6). La Tarumba llevó a cabo numerosas funciones por las zonas de la Andalucía «nacional»: Huelva, Sevilla y Cádiz, y en su repertorio llevaban varios entremeses de Cervantes (La guarda cuidadosa, El retablo de las maravillas) además del atribuido Los dos habladores y del atribuido a Lope de Vega, El degollado fingido, además del Primer y Segundo Pliego de romances, de Rafael Duyos: un programa muy deudor de La Barraca, donde se habían programado los mismos entremeses cervantinos y se había llevado a cabo una función de exaltación romanceril con el título de La fiesta del romance. Aun cuando sus primeras actuaciones se limitaron a Andalucía, La Tarumba fue ampliando sus actuaciones a otras zonas de la España «liberada» (Gómez Díaz, 2006; Martínez Cachero, 2000). Hay testimonios de su presencia en Ávila (Guirao Godínez, 2007: 112-113) y también de la ampliación del repertorio con el auto Las bodas de España, para el que realizó una brillante escenografía Pepe Caballero (Madrigal Neira, 2001: 193). A Caballero se le debe también el logotipo de la compañía en el que aparece el siguiente rótulo: TEATRO UNIVERSITARIO FALANGE ESPAÑOLA. En diciembre de 1937 se presentó en Sevilla La Tarumba como Teatro de la Falange, con un espectáculo titulado Belén, compuesto por romances y canciones de Navidad, danzas antiguas pastoriles y el Auto sacramental de los Reyes Magos [sic]. Hacia las mismas fechas un anuncio publicado en el $A B C$ sevillano (7-XII-1937) rezaba así: «El buen teatro es la mejor expresión de la cultura de un pueblo. Ved La Tarumba, teatro de Falange Española Tradicionalista y de las JONS, esta tarde, en el Coliseo España, a beneficio de Navidad en el Frente». En enero de 1938 La Tarumba se presenta en el teatro Cervantes de Segovia, como acto solemne de clausura del II Consejo Nacional de las Secciones Femeninas de FET y de las JONS, con asistencia de los consejeros nacionales Pedro Laín Entralgo, Dionisio Ridruejo, Pilar Primo de Rivera, Raimundo Fernández Cuesta y otros jerarcas falangistas. En abril de ese mismo año el grupo se presenta con su nombre originario como Teatro de la Falange. 
Es un momento de confusión en que, como vemos, el nombre originario convive con otros que hacen referencia a su condición de teatro universitario, además de su dependencia de Falange Española. Entrevistado Luis Escobar en diciembre de 1938, presentaba así el Teatro Nacional de Falange Española:

Presentamos algún entremés de Cervantes, obras de Juan Ruiz de Alarcón y de Calderón de la Barca, y algunos autos sacramentales entre ellos el llamado Las bodas de España [...]. Tenemos también un espectáculo mixto de canciones y romances de sabor popular [...] Aspiramos con esto último a despertar el interés por el folklore nacional tan rico en matices y a la vez tan olvidado [...] Cuando hayamos conseguido la divulgación del teatro clásico empezaremos por el moderno (Guirao Godínez, 2004: 437).

En esta misma entrevista Escobar anunciaba la creación dentro del SEU de «teatros universitarios», y concluía: «Nosotros, claro está, seremos sus orientadores» (Guirao Godínez, 2004: 238). En este juicio de Escobar se observa claramente la distinción entre lo que pronto iba a llamarse Teatro Nacional de FET y de las JONS y el TEU. El primero se presentó con dos autos sacramentales: El hospital de los locos, de Valdivielso y La cena del rey Baltasar, de Calderón de la Barca (Foxá, 1938; Araujo Costa, 1939, 1939; Jorge de la Cueva, 1939; José de la Cueva, 1939). Este segundo auto serviría para inaugurar el Teatro Nacional ya en su sede del María Guerrero (Jorge de la Cueva, 1940). Para mayor confusión el teatro que dirigía Felipe Lluch en el Español de Madrid se llamaba también Teatro de la Falange, y bajo ese rótulo presentó el espectáculo patriótico España Una, Grande y Libre (1940).

Obsérvese que en todos estos proyectos iniciales de un teatro nacional o falangista asoma, de una u otra forma, su condición universitaria, sin duda por la presencia dominante del SEU, a veces incluso en capitales de provincia que no contaban con universidad. Es el caso de Ávila, donde desde 1938 funcionaba una compañía con el nombre de El Retablo, Teatro Universitario del SEU de Ávila. En otros medios se habla simplemente de Teatro Universitario del SEU. En Yugos y flechas se afirma que «una de las tendencias más importantes de los estudiantes nacionalsindicalistas es la creación del Teatro Universitario SEU, que es un medio para lograr en la nueva España el grado siquiera sea mínimo de la cultura» (apud Guirao Godínez, 2004: 423). Anuncios publicados en la prensa tanto nacional como local nos hablan del clima efervescente que se vive a principios de 1939, cuando ya se otea la victoria de Franco, en orden a crear un auténtico teatro universitario. Una reunión del SEU en Sevilla, a primeros de 1939 lleva como punto 2 en el orden del día el siguiente asunto:

Se ordena a todas las camaradas que durante el año 1938 han tomado parte en las clases de Gimnasia Rítmica, Orfeón y Teatro Español Universitario, se 
presenten en nuestro local de Doña María Coronel, hoy jueves, día 19, a las 6,30 de la tarde, para un asunto de gran interés (ABC-Sevilla-19-I-1939).

Queda clara que la marca Teatro Español Universitario (TEU) es un producto temprano fruto de la colaboración entre el SEU y otras instituciones falangistas, como las Organizaciones Juveniles de FET y de las JONS. Al poco de terminar la guerra comienza a funcionar un Guiñol del TEU, promovido por el SEU de Magisterio (Madrid), con un programa de edificantes piezas, cuyo título más emblemático es Periquito contra el monstruo de la democracia, de Alejandro Blas y Agustín Embuena, destinadas a catequizar a los niños en los principios del «glorioso Movimiento Nacional» (Araujo Costa, 1939).

El Teatro de la Organización Juvenil se presenta, en marzo de 1940, en el teatro Fontalba de Madrid con una función para niños constituida por un paso de Lope de Rueda -El licenciado Xáquima-, la Farsa sacramental de la residencia del hombre y el Auto de la Pasión, de Lucas Fernández (Araujo Costa, 1940). La Sección Femenina contó también con su rama dramática, llamada El Carro de la Farándula, aunque parece que fue bastante efímera. En julio de 1939 se presentó en el Patio de los Reyes del monasterio de El Escorial con el auto de Lope, Del pan y del palo, con la dirección artística de Manuel Comba (Araujo Costa, 1939b). Y en el mismo mes se presentó en el Español de Madrid con El hijo pródigo, de Lope, y La guarda cuidadosa, de Cervantes. En diciembre del mismo año, esta compañía representó en el Círculo de Bellas Artes La Aulularia de Plauto, con la dirección técnica de Margarita Rosel y la dirección escénica de José Franco, viejo actor de la TEA de Rivas Cherif, además de Manuel Parada como director musical, y Gerardo Atienza como encargado de la coreografía.

\section{Modesto Higueras}

Ante este batiburrillo de compañías, nada mejor que acudir a la memoria de Modesto Higueras, primer director del Teatro Español Universitario a nivel nacional, pero que con anterioridad había tenido a su cargo la dirección del Teatro de las Organizaciones Juveniles:

En octubre de 1939 se crea como teatro escuela el cuadro artístico de las Organizaciones Juveniles con el objeto de aficionar a sus afiliados a nuestro teatro y proyectarse tanto entre ellos, albergues, locales de estudio, como en el exterior.

Durante los meses de octubre a diciembre de 1939 y todo el año de 1940, realizó este teatro juvenil una intensa campaña por ciudades y albergues.

Este teatro ambulante montó: 
- La comedia de la muerte del rey don Sancho y reto de Zamora, de Juan de la Cueva

- La residencia del hombre, farsa sacramental anónima del siglo XVI

- El Auto de los Reyes Magos, anónimo del siglo XII

- Los habladores, entremés de la escuela cervantina

- La guarda cuidadosa, de Cervantes

- La tierra de Jauja, Las aceitunas, entremeses de Lope de Rueda

- Historias de Navidad, montaje realizado sobre canciones y bailes populares

- El cartero del rey, de Rabindranatah Tagore.

La formación de sus actores estaba lejos del profesionalismo auténtico, pero la correcta dicción y el entusiasmo y fe de sus interpretaciones hizo pensar en la creación de un teatro más completo y que, partiendo de la universidad, pudiera ya ofrecer la auténtica renovación con arreglo a las teorías del teatro universal, de que tan necesitado estaba nuestro teatro, pero es indudable que en aquellos momentos se incorporaba a la reconstrucción de su patria.

Es interesante destacar que en el año 1940 este teatro juvenil se adelantó a conmemorar antes que nadie el octavo centenario del Poema del Cid, presentando la figura del primer caballero castellano a través de la famosa comedia del sevillano Juan de la Cueva.

$\mathrm{Al}$ atardecer, o a la luz de las higueras, del fuego del campamento, con sus compañeros sentados en corro, este teatro ambulante levantaba sus sintéticos decorados, se caracterizaban, y representaban sus farsas al igual que aquel batihoja de Lope de Rueda, iniciador y padre de nuestro teatro popular (Higueras, 1965).

Por fin, en 1940, Higueras consigue realizar su sueño: dirigir un teatro que llevase la impronta indeleble del proyecto en que se involucró de joven: La Barraca. Su recuerdo al maestro que le enseñó el camino permanece al cabo de los años, como escribe en 1965, por cierto en tercera persona:

A veces la intuición realiza hechos concretos que ni la más fuerte meditación sabe llevar a la práctica y, sin embargo, es tan sencillo...

Un hombre intuye lo mismo que el poeta granadino: la salvación del teatro mediocre, el anquilosamiento nuestro, y que para partir de una renovación, no puede partir más que desde la universidad. Los alumnos de Filosofía y Derecho principalmente darán la clave. José Miguel Guitarte, jefe nacional del SEU, hombre político y no dedicado a la poesía ni al arte dramático, decide dar un impulso a nuestro teatro nacional, ya que su sensibilidad a ello le empujaba, y llama a Modesto Higueras, que tenía la experiencia lorquiana y su propia formación, realizada recientemente en el Teatro de las Organizaciones Juveniles, para que cree el Teatro Nacional Universitario y asesore los otros del distrito.

Se convocó a los estudiantes y se realizaron diversas pruebas dramáticas, así como una serie de preguntas sobre el concepto del teatro, su vocación de intérprete y su dedicación sin pérdida de tiempo en relación con sus estudios. A los dos meses de la estructuración del Teatro Nacional Universitario y los 
ensayos correspondientes, se debutó en el Teatro Español de Madrid con un programa extraordinario, ya que se ofreció la comedia en tres actos de Tirso de Molina La mujer por fuerza y el estreno de Navidades en la casa Bayard, de Thornton Wilder. El éxito fue grande porque los actores universitarios recitaron con arreglo a un sentido auténtico del verso, sin énfasis y rehuyendo el divismo en bien del grupo.

Respecto a la obra de Wilder fue un impacto ante los espectadores, ya que era desconocido el autor norteamericano en nuestros medios teatrales y, sobre todo, por plantear en un feliz ensayo en el que resuelven en el espacio y en el tiempo la limitación y la duración en un acto noventa comidas de Navidad en una casa burguesa del Nuevo Hampshire.

[...]

El TEU nació al fusionarse el SEU del cual dependía, pasó directamente a depender de la Asesoría Nacional de Cultura y Arte del Frente de Juventudes, y es aquí donde, después de tres años de formación y madurez, realiza los montajes más diversos y es donde, sin ser escuela de formación de actores y actrices exclusivamente, despierta vocaciones dando a nuestra escena intérpretes que hoy son figuras en la radio, cine, televisión, etc.

La fusión a la que se refiere Higueras es la del SEU con el Frente de Juventudes, y todas las actividades entonces pasaron a la Asesoría Nacional de Cultura y Arte desde abril de 1944. Y de ahí a 1951, en que cesa en el cargo para marchar por una breve temporada a Santo Domingo para dirigir el Teatro Nacional. Antes de marcharse, el 27 de diciembre de ese año, Higueras recibe un gran homenaje en el Teatro Infanta Beatriz. Para la función se escogieron el sainete de Ricardo de la Vega, Pepa, la frescachona, y el auto sacramental de Calderón, La vida es sueño. Hacía casi veinte años desde que Modesto se había estrenado como actor de La Barraca con esta misma pieza, bajo la dirección de Federico García Lorca, su maestro siempre inspirador (Valero López, 1985). Hay que suponer al fundador del TEU nervioso y emocionado por revisitar aquella epifanía, que fuera tan decisiva en su vida como en la historia del teatro español contemporáneo. Aunque el nombre de su maestro no apareciera ni en el programa ni en la función, Higueras debió pensar en él, mientras asistía entre bambalinas a la representación. Cabe también suponer que, tras el personaje de La Sombra, no pudiera sino ver la propia sombra de Federico interpretando -parece que no muy bien- a la criatura maldita por excelencia del auto.

A esta función de homenaje se sumaron antiguos componentes del TEU, ya consagrados en la escena nacional, como María Jesús Valdés, Nati Mistral, Valeriano Andrés y José Luis López Vázquez. Entre aquel espectáculo de 1932 y este de 1951 había, pues, afinidades evidentes, pero también-jay!-diferencias enormes en lo que se refiere a las libertades. Aun así, el trabajo de Modesto 
Higueras durante esos años demostró que el teatro era capaz de vencer inconvenientes e intolerancias.

De la figura de Modesto Higueras hizo una semblanza muy útil Manuel Gómez García (2006), pero aún está aguardando la monografía que lo valore como merece este gran director que, salvo una breve temporada al frente del Teatro Español, estuvo casi siempre relacionado con el teatro independiente y el teatro de cámara. Como complemento de esa monografía, que seguramente saldrá del proyecto i+d TEU, habrá que contar con la obra escrita de Higueras: varios artículos (Higueras, 1941, 1944a, 1944b, 1944c, 1945, 1948, 1964, 1977) y una memoria, depositada en la Fundación Juan March, titulada El teatro de ensayo (1965). En estos escritos Higueras trató temas relacionados con el estado del teatro en la España de posguerra y sus posibles soluciones. En un trabajo de 1944, sobre «lo espectacular en los teatros juveniles», se refiere a «nuestra escena enferma», para concluir que «el teatro ha sido, debe ser un espectáculo para multitudes, y así, el teatro de ensayo no nos interesa siempre y cuando no esté destinado a la formación de un gran público, a la creación de un gusto, una tendencia determinada con la intención de servir a la masa de espectadores desorientados» (1944b). Higueras tiene un concepto parecido al de Lorca, de modo que apuesta decididamente por el teatro breve, como consumada muestra de teatro popular, así los pasos de Lope de Rueda, tan opuestos a «las comedias teatraleras y vulgares que en gran mayoría se nos ofrecen en la ciudad» (1944c). A pesar de su militancia falangista, no hay en Modesto Higueras una utilización mostrenca de la ideología en sus puestas en escena, muy probablemente porque tenía siempre muy presente el ejemplo que había supuesto Lorca. Toda su trayectoria posterior al frente de teatros nacionales o, más habitualmente, de teatros de cámara y aulas de teatro demuestra que en su personalidad primó lo profesional sobre lo político.

\section{Para un teatro falangista}

Antes de comentar la actividad provincial de los TEUs convendrá hacer un examen bibliográfico de las fuentes primarias y secundarias con relación a los postulados ideológicos del teatro falangista que perseguía el SEU, cuya maquinaria conocemos perfectamente gracias a los estudios de Miguel Ángel Ruiz Carnicer (1996a, 1996b). Sobre cómo debía ser el teatro falangista existe un ensayo impagable del siempre impredecible Tomás Borrás (1942, 1943; sobre Borrás, véase Lloret Martín, 2015), además de algunos escritos durante la guerra por Federico Torralba Soriano (1937), Manuel Machado (1938a, 1938b), Juan Tébar (1939) y Gumersindo Montes Agudo (1937), muy conocido luego por su actividad en la Junta de Censura, y otros posteriores (1944a). 
Tras el pionero trabajo de José-Carlos Mainer (1970), conocemos muy bien la poética del teatro fascista (Mermall, 1973; Berghaus, 1996; Linares, 1996; Wahnón, 1996). Naturalmente los postulados de este teatro siguen de cerca la teoría fascista expuesta por Ernesto Giménez Caballero en Arte y estado (1935), que más o menos sigue Gonzalo Torrente Ballester en sus ensayos de 1937, 1941a, 1941b, 1941c (Yamaguchi, 2002; Pérez Bowie, 2009; Huerta Calvo, 2010). Son de gran interés, asimismo, las críticas teatrales publicadas en Arriba de Antonio de Obregón (Mahanta Kébé, 2002). Vale por un resumen de todo ello la monografía que Víctor García Ruiz dedicara a Felipe Lluch (2010).

\section{Los TEUs provinciales}

Junto al TEU nacional, radicado en Madrid y dirigido por Modesto Higueras y después por su hermano Jacinto, antiguo actor también de La Barraca (J. Higueras, 1996), fue importantísima la actividad llevada a cabo en los TEUs de provincias. Es el momento de considerar los primeros acercamientos al fenómeno tanto desde el punto de vista nacional como provincial, empezando por el muy temprano de Suelto de Sáenz (1964) hasta el libro coordinado por Luciano García Lorenzo (1999), con varias colaboraciones de interés, entre las cuales destaca la de conjunto que lleva a cabo Eduardo Pérez-Rasilla (1999), el testimonio de Gonzalo Pérez de Olaguer (1999) y otras que se irán citando con relación a los distintos distritos universitarios.

El de Barcelona tiene una impecable y sintética descripción en Aznar Soler (1999), y para su debida contextualización es imprescindible acudir al libro de Enric Gallent (1985). El nombre del poeta y filólogo Guillermo Díaz Plaja, durante muchos años director del Instituto del Teatro, tuvo bastante protagonismo en sus inicios (Díaz Plaja, 1952), así como el del director José Antonio de la Loma (1948a, 1948b, 1948c, 1949a, 1949b). Alejandro Bellver, desde las páginas de la revista Barcelona teatral, siguió muy de cerca las actividades del TEU catalán (Bellver, 1948b, 1948c). El TEU de Valencia, vinculado en años no demasiado lejanos a la figura de José Sanchis Sinisterra, cuenta también con una aproximación en un libro colectivo (VV. AA, 1993; Sirera, 1993), en el que la colaboración de Aznar Soler y Fernanda Mancebo (1993) estudia el precedente del TEU valenciano en El Búho, que dirigiera Max Aub. Más completa es la que trata el TEU de Zaragoza, gracias al libro coordinado por Jesús Rubio Jiménez (2000a, 2000b) y, dentro de él, a la documentada colaboración de Miguel Ángel Ruiz Carnicer (2000a) por lo que se refiere a la etapa primera, en la que llama la atención cómo en el curso 1939-40 pudo llevarse a cabo la representación de La zapatera prodigiosa y Bodas de sangre. Sin duda, el de Zaragoza sería ya a partir de los 50 uno de los TEUs más activos con el 
protagonismo de dos poderosos directores, como son Alberto Castilla y Juan Antonio Hormigón (2000a), a quien se debe una casi increíble puesta en escena de los dos únicos cuadros de El público que, a principios de los años 60, eran conocidos. El TEU de Murcia tiene también una brillantísima tradición, desde dos directores históricos como Alberto González Vergel (2008; Facio, 2008) y Ángel Fernández Montesinos (2008) hasta César Oliva (1975). Toda esta trayectoria nos es ahora perfectamente conocida gracias a la tesis doctoral de Nieves Pérez-Abad (2017). Otra tesis doctoral de María Jesús Bajo Martínez (2016), que no hemos podido consultar todavía, se ocupa del TEU de Sevilla, sobre el cual había ofrecido ya algunos adelantos (1996, 1999). Hoy por hoy es la investigadora más capacitada para ofrecer una panorámica completa de lo que fue el TEU en toda Andalucía (para Granada véase también Molinari, 2006; Delgado, 2011). Otros TEUs importantes fueron el de Salamanca (Ruiz Valderrama, 1946; Pérez Bowie, 1999) y el de Santiago (Salgueiro, 1999).

\section{Repertorio}

El objetivo del proyecto TEU. Primera etapa es elaborar una cartelera lo más completa posible. Siguiendo el ejemplo de La Barraca, los clásicos gozaron siempre de un gran protagonismo: Lope de Vega, La siega; Los locos de Valencia, La estrella de Sevilla (Interino, 1951). Santiago el Verde (1951). Miguel de Cervantes: La guarda cuidadosa El retablo de las maravillas, La cueva de Salamanca (Ródenas, 1942a; Marqueríe, 1944b). Luis Quiñones de Benavente: Los sacristanes burlados, Los borrachos. Tirso de Molina: La mujer por fuerza (Cueva, 1940); El burlador de Sevilla (Anónimo, 1942) El colmenero divino (Anónimo, 1944e). Un año después se repone la obra, acompañando a la ópera Don Juan [Don Giovanni] de Mozart, esta última adaptada por José María Franco. La villana de Vallecas fue adaptada por José García Nieto (Marqueríe, 1950a). En 1946, para inaugurar el curso dramático universitario, Higueras escoge La prudencia en la mujer, con música de García de la Vega y coreografía de Pilar Monterde. No falta tampoco Quevedo, de cuyos sueños y prosas festivas parece que José Franco hizo una refundición con el título de Las mujeres en la calle, el portentoso y el alquimista (1945). Guillén de Castro: Las mocedades del Cid. Calderón: La vida es sueño, tanto la tragedia como el auto sacramental; El santo rey don Fernando y El pleito matrimonial del alma y el cuerpo (Ródenas, 1943a; Sánchez Camargo, 1942, 1943b). Escobar había recuperado en 1939 al muy olvidado Valdivielso al adaptar El hospital de los locos, y en 1942 es Higueras quien lleva a cabo una refundición de otro auto sacramental de este autor, El hijo pródigo (Ródenas, 1942a). En 1945 se presenta un espectáculo bajo el título de La vida del estudiante español en el teatro, conformado por las siguientes 
piezas: El paso de la cazuela, de Lope de Rueda; La cueva de Salamanca, de Cervantes; El maestro de rondar, de Ramón de la Cruz; Pepa la frescachona, de Ricardo de la Vega, y Exámenes, de Antonio de Lara Tono. Modesto Higueras, con la colaboración de Pío Ballesteros, realiza un montaje sobre villancicos de los siglos XV, XVI y XVII con el título de Retablo del nacimiento de Nuestro Señor Jesucristo (1948). El teatro breve del siglo XIX aparece, en efecto, con el mencionado sainete de Ricardo de la Vega y el drama burlesco de Vital Aza y Estremera, El medallón de topacios (amor, parentesco y guerra).

Pero también desde un primer momento se intentó incorporar autores contemporáneos e, incluso, nuevos dramaturgos, «nuevos autores para un nuevo teatro», como escribiera José García Nieto (1944) y también Enrique Llovet (1944). Como en este mismo volumen estudia Sergio Santiago, la primera obra programada por Modesto Higueras para el TEU de Madrid fue El otro, de Miguel de Unamuno, el 1 de febrero de 1940 (Araujo-Costa, 1940; Cueva, 1940). Gonzalo Torrente Ballester: El casamiento engañoso (Anónimo, 1943a; Ródenas, 1943b; Haro Tecglen, 1943; Sánchez Camargo, 1943a; Hermans, 1992). Víctor Ruiz Iriarte: Un día en la gloria (Ruiz Iriarte, 1943a, 1943b, 1944a; Anónimo, 1944b; Ríos Carratalá, 2009). Julio Angulo: Ático izquierda. José García Nieto: Retablo del ángel, la pastora y el hombre (1944). Esta obra apareció en la revista Garcilaso, y fue estrenada en el Teatro Español, en noviembre de 1944, con decorados de José G. Ubieta y música de Mariloli Higueras. Julián Ayesta: El tímido Serafin (Marqueríe, 1944b). Julián Ayesta y Alberto Crespo: La ciudad ajena (1944). José Franco: El agricultor de Chicago (1946).¿Dios con nosotros?, de Vicente Escribá y Armando Ocano. Fernando Vizcaíno Casas: La senda iluminada. Lope Mateo: Ojos claros, serenos... (Acorde, 1949)

En cuanto al teatro extranjero: Rabindranath Tagore: El cartero del rey. George Bernard Shaw: Los despachos de Napoleón, Santa Juana. Thornton Wilder: Navidades en la casa Bayar. John Erskine: La vida privada de Elena de Troya. Otro autor norteamericano es Mark Twain, una de cuyas narraciones, El agricultor de Chicago, adaptó José Franco. De J. M Synge, Jinetes hacia el mar (1947). Enrico Fulchignoni: El ayunador (1942). Muchas de estas obras aparecieron publicadas en la revista falangista $\mathrm{Haz}$, donde también se publicaron otras piezas de autores extranjeros, entre ellos los franceses Henri de Montherlant, Pasifaé (1944), y Sodoma y Gomorra, de Jean Giraudoux (1944).

Ha estudiado de forma muy detenida Víctor García Ruiz (1997, 1998, 2002) el resurgimiento del auto sacramental en los años 40 , sobre el cual escribió Felipe Lluch (1943). Ángel Valbuena Prat (de Paco, 2000a), Ángel González Palencia (1943), Eugenio Frutos Cortés (1947, 1948, 1952), y José Corrales Egea (1945) fueron grandes valedores críticos del género. En 1944 el 
TEU de Salamanca presentó en el Teatro Liceo El sueño del anacoreta, un auto sacramental del sacerdote José S. Martín Blanco. Un año después el TEU de Barcelona apuesta por la anónima Farsa sacramental de la Fuente de la Gracia, del siglo XVI. La obra fue presentada por el catedrático José María Castro y Calvo (Sanvisens i Marfull, 1952). En la labor de recuperación de los autos hay que poner también a Nicolás González Ruiz, habitual adaptador de clásicos para el TEU (1946, 1953a). Sobre la recepción de los autos, en general, véanse los trabajos de García Lorenzo (2002) y de García Lorenzo y Muñoz Carabantes (2001).

\section{Escenógrafos y figurinistas}

Son notables los escenógrafos que contó el TEU. Higueras y otros directores siguieron en este sentido el camino trazado por García Lorca en La Barraca: la representación teatral debía ser un acontecimiento artístico que implicase no solo la recitación del texto sino también una puesta en escena lo más brillante posible. José Luis López Vázquez destacó como escenógrafo y figurinista desde los primeros montajes; por ejemplo, en el de los entremeses de Cervantes y Quiñones de Benavente, La guarda cuidadosa y Los sacristanes burlados, respectivamente (1942). En un artículo publicado en la revista Haz, Fuentes Segura (1945) menciona al que sería después grandísima figura de la interpretación (Fernández Oliva, 1988) entre escenógrafos como José Caballero y Emilio Burgos.

\section{El TEU y los teatros independientes}

Sobre estos grupos escribió José Gordón Paso un interesante ensayo (1959) en que lleva a cabo una interesante síntesis histórica del papel desempeñado en la historia reciente por grupos que, bien el ámbito universitario o en el independiente, son fundamentales para comprender la evolución del teatro luego de la Guerra Civil: Caracol, Teatro Escuela de Arte (TEA), La Barraca, Anfistora. Después de la guerra, el TEU, que «hacía una labor de revisión clásica muy interesante en el campo universitario», y los grupos propiamente experimentales: Arte Nuevo (Fraile, 1989; de Paco, 1988); Aznar Soler, 2016), La Carátula, El Duende, El Candil, el Teatro de Estudio, de Juan Germán Schroeder (Coll, 1945) y el Teatro Nacional de Cámara y Ensayo, que dirigió durante unos años Modesto Higueras. Gordón relaciona la irrupción de estos grupos con la necesidad de formar un público nuevo, opuesto al público burgués, caracterizado de este modo tan radical por el autor. 
Hoy el teatro cuenta con un público mucho más preparado intelectualmente y en esto también los teatros experimentales y de cámara hicieron una gran labor en España. El teatro experimental empezó la labor de terminar aplastando a un público burgués que es uno de los cánceres que tiene la sociedad española [1959: 19].

La crítica del público burgués es, pues, una de las afinidades más notables entre los grupos de teatro experimental y los universitarios procedentes del ideario falangista, radicalmente antiburgués. El autor quizá más destacado de Arte Nuevo, Alfonso Sastre, coincide en esta misma perspectiva, «la náusea ante el teatro burgués», representado por Benavente, Torrado, Muñoz Seca y Marquina, entre otros (Doménech, 1964). Luego de la disolución de Arte Nuevo, Sastre y Quinto $(1950,1964,1999)$ firman el manifiesto por un Teatro de Agitación Social (TAS), en el que proponían la introducción en España de los grandes autores contemporáneos, como O'Neill, Miller, Sartre, Brecht... Muchos de ellos entrarían así en el repertorio de los TEUs. Con relación a Sastre no hay aún un estudio que aborde sin tapujos la etapa filofalangista del autor, cuyas primeras colaboraciones tienen lugar en periódicos y revistas muy vinculados al régimen, como Arriba, La Hora (Caudet, 1984), El Español, etc. En alguno de esos artículos, Sartre se interesa, por ejemplo, por las relaciones entre el teatro y la universidad (Sastre, 1949, 1950d). Paula Martínez-Michel (2003) pasa de puntillas por esta etapa colaboracionista del gran dramaturgo que derivaría con los años en posiciones políticas totalmente extremosas, al igual que -pero en la acera contraria- Alfonso Paso (Payá Beltrán, 2015).

De otras muchas facetas de lo que fue el TEU en su primera etapa da constancia la bibliografía que sigue y que es, hasta el momento, la más completa que se ha reunido sobre el tema de esta investigación.

\section{Referencias bibliográficas}

A.P., «El Teatro de Estudio será llevado a la universidad. Un gran proyecto de renovación escénica que aborda el SEU», Juventud, 56 (1944), p.8.

A.Z., «Barcelona. Actuación de la Compañía del TEU, de Madrid», LVE (4-II-1947), p.10.

Acorde, «Novedades teatrales de la semana. Alcanza un buen éxito en el Beatriz un poema escénico de Lope Mateo», Hoja oficial del lunes (21-XI-1949), p.2. Aguilera SASTRE, Juan, «Antecedentes republicanos de los teatros nacionales», Historia de los teatros nacionales, 1939-1962, Madrid, INAEM, 1993a. 
—, «Felipe Lluch Garín, artífice e innovador del teatro nacional español», en Historia de los teatros nacionales, 1939-1962, Madrid, INAEM, 1993b.

—, «Luis Escobar, director del Teatro Nacional María Guerrero de Madrid», en Luis Escobar y la vanguardia, Madrid, Comunidad de Madrid, 2001, pp.13-54.

—, El debate sobre el Teatro Nacional en España (1900-1939): Ideología y estética, Madrid, CDT, 2002.

-, y Aznar Soler, Manuel, Cipriano de Rivas Cherif y el teatro español de su época (1891-1967), Madrid, Publicaciones de la ADE, 1999.

AlBerT, Mechthild, Vanguardistas de camisa azul: la trayectoria de los escritores Tomás Borrás, Felipe Ximénez de Sandoval, Samuel Ros y Antonio de Obregón entre 1925 y 1940, trad. C. Díez Pampliega y J. R. García Ober, Madrid, Visor, 2003.

AlCOCER, José Luis, Radiografía de un fraude: notas para una historia del Frente de Juventudes, Barcelona, Planeta, 1978.

AldECOA, Ignacio, «Lo que nos dice Pepe Bernalt. Pianista, compositor y formador del coro del Frente de Juventudes», Cátedra, 10 (IV-1945).

Almagro Díaz, Antonio, El pueblo español y su destino, Madrid, Delegación Nacional del Frente de Juventudes, 1952.

AlOnso Cortés, A., «Teatro en la Universidad», La Hora, 24 (15-IV-1949), p.11.

ANÓNIMO, «Coliseo: La Tarumba en el beneficio de la Casa del Flecha», ABC -Sevilla- (31-XII-1936), p.16.

—, «La Tarumba y la Bética de Cámara en el Coliseo», ABC -Sevilla- (25-I-1937a), p.21.

—, «Otra admirable actuación de La Tarumba», ABC -Sevilla- (22-IV-1937b), p.20.

—, «Coliseo España: La Tarumba por Navidad en el Frente», ABC -Sevilla- (8-XII1937c), p.24.

—, «Lope de Vega: La Tarumba», ABC -Sevilla- (8- II-1938a), p.21.

—, «Pregón de juventud», Azul, 503 (19-V-1938b), p.1.

—, «Teatro universitario», Azul, 503 (19-V-1938c), p.1.

—, «Extraordinario acontecimiento teatral. La Compañía del Teatro Nacional actuará en Zamora», Heraldo de Zamora (7-XI-1938d).

- «Esta tarde se presentará en el Tívoli el Teatro Nacional de Falange», LV (24-II-1939a).

-, «En el Tívoli. La vida es sueño, de Calderón, uno de los más resonantes éxitos del Teatro Nacional de Falange», LV (2-III-1939b), p.3.

—, «Teatro de ensayo», Haz, II/16 (X-1939c), pp.30-31.

—, «Teatro Nacional de la Falange [La cena del rey Baltasar], Arriba (27-VI-1939d).

- , «Brillantes actos en Soria. La festividad de santo Tomás de Aquino [La dama boba, de Lope de Vega]», El Avisador numantino, 5643 (8-III-1939e), p.2.

—, «El Teatro Español Universitario del SEU se desplaza a Sevilla», Azul, 831 (11-VI-1939f). 
—, «El TEU quiere educar, no entretener», Azul, 858 (13-VII-1939g).

—, «El Teatro Universitario del SEU 'El Hombre bueno' se presentará mañana en el teatro Principal [Zamora]», Imperio, 714 (10-III-1939h), p.2.

—, «Hoy debuta El hombre bueno, Teatro Universitario del SEU», Imperio, 715 (11-III-1939i), p.2.

—, «La actuación del 'Hombre bueno', Teatro Universitario del SEU», Imperio, 716 (12-III-1939j).

—, «Mérito y significado del Teatro Nacional de la Falange», LV (23-II-1939).

—, «El currinche, la crítica y el público», Haz, 22 (1940a), pp.30-31.

—, «Teatro de la Falange. España Una, Grande y Libre» ABC -Sevilla- (7-V-1940b).

—, «El TEU (Barcelona)», LVE (29-II-1940c), p.6.

—, «El TEU (Barcelona)», LVE (1-III-1940d), p.5.

-, «Descenso de la cultura», España popular. Semanario al servicio del pueblo español, I/19 (25-VI-1940e), p.7.

- «El Teatro Guiñol será introducido por el SEU en todas las Escuelas de España», HZ (27-IV-1940f).

—, "El Teatro Español y los productores españoles", Haz (20-I-1941), p.15.

—, «El Teatro Español Universitario [El burlador de Sevilla]», Nueva Alcarria (19XII-1942), p.4.

—, «El casamiento engañoso», Haz, IV/8 (1943a), p. 31.

—, «Navidades en la Casa Bayard», Haz (1943b).

—, «El TEU procura la exaltación de nuestros mejores valores clásicos», LP (4-V-1943c).

—, «Medios y fines de un teatro universitario», Juventud, 41 (1944a), p.17.

-, «Actuación del Teatro Universitario. Estreno de Un día en la gloria y representación de La vida es sueño», Juventud, 41 (1944b), p. 8.

—, «Actuación del TEU en el Español», Juventud, 35 (1944c), p.8.

—, «Actividades del TEU de Valencia», Juventud, 31 (1944d), p.8.

—, «Representación de un auto sacramental de Tirso en la Universidad», LVE (31-V-1944e), p.8.

—, «Los actos de la festividad de Santo Tomás», Estilo, II/12 (24-III-1945a).

- «Clausura del curso en la Universidad Literaria. Auto sacramental interpretado por el Teatro Universitario», LVE (3-VI-1945b), p.12.

—, «Una versión de Modesto Higueras de La prudencia en la mujer», ABC (2-XI-1946.

—, «Homenaje de la juventud a la memoria de [Manuel] Machado en el teatro Lara», Hoja oficial del lunes (24-III-1947a), p.6.

—, «TEU. Concurso de obras teatrales», BT, 398 (9-IX-1948a), s.p.

—, «Modesto Higueras es el artífice del TEU», Pueblo (10-VII-1948b).

—, «The Theatrical Year», en Spain (Madrid, 1949), pp.130-134. 
—, «La representación de teatro clásico en el Palacio del Infantado constituyó un acontecimiento artístico», Nueva Alcarria (10-VI-1950), p.6.

—, «El TEU estrena Tres sombreros de copa», Alcalá, 22 (10-XII-1952a), p.4.

—, «Teatro de España en tierras de América», Mundo Hispánico, 48 (1952b), p. 49.

- «La dirección de uno de los teatros nacionales a Modesto Higueras», Solidaridad Nacional (28-X-1952).

—, «El Teatro Popular Universitario clausura esta noche el ciclo 1953 con el estreno de El jugador, de Hugo Betti», ABC (10-VI-1953a).

-, «La Agrupación del Teatro Popular Universitario salió ayer para Mérida: el domingo representará en el Teatro Romano Fedra, de Séneca», Hoy (6-XI-1953b).

-, «La llanura, de don José Martín Recuerda fue presentada anoche en el Español por el Teatro Universitario de Granada», ABC (5-III-1954a).

- «Constituyó un éxito inmenso la presentación del TEU: representó en el Gran Teatro La hidalga del valle», Hoy (26-XI-1954b).

—, «Teatro Popular Universitario», Alcalá, 49 (1954c), p.4.

- «Modesto Higueras y su magnífica labor al frente del Teatro Nacional de Cámara», Informaciones (31-III-1956).

—, «Modesto Higueras», ABC (9-IV-1964).

-, «Veinte años al servicio del teatro: la compañía Lope de Vega y José Tamayo: del teatro universitario al teatro comercial», $A B C$ (25-X-1966).

—, «Modesto Higueras dirigirá el nuevo café-teatro Canotier», Arriba (10-I-1971).

—, Treinta años de teatro español (1939-1969), Toledo, Imprenta Provincial, s.a.

Antolín, Mario, «En la muerte de Modesto Higueras», ABC (14-XI-1985).

—, [2000], «El TEU de Zaragoza en el recuerdo», en Rubio Jiménez, 2000a, pp.175-177.

APARICIO, Juan, La Falange ante la universidad. Discursos y conferencias del V Consejo Nacional del SEU, Madrid, 1942.

ARAGONÉS, Juan Emilio, «Tres caminos del teatro: España, sin teatro», Revista, 86 (1953), p.14.

—, «Lecturas teatrales, dialogadas, en la universidad», Alcalá, 68 (25-III-1955a), p.14.

—, El teatro y sus problemas, Madrid, RESAD, 1955b.

Araujo-Costa, Luis, «En el Patio de los Reyes de El Escorial. Representación del auto sacramental de Lope de Vega Del pan y del palo» ABC (1939a).

—, «Actuación de El Carro de la Farándula, en el Español», ABC (1939b).

—, «El Teatro Nacional de FET y de las JONS en el Capitol: El hospital de los locos», $A B C(15-I V-1939 c)$.

-, «El Teatro de FET y de las JONS en el Retiro. Representación de La cena del rey Baltasar», ABC (23-VII-1939d).

—, «El guiñol del TEU», ABC (11-VIII, 1939e), p.19. 
—, «Fontalba: Teatro de la Organización Juvenil», ABC (21-III-1940a).

—, «Español: una representación de El Otro», ABC (1-II-1940b), p.15.

AYESTA, Julián, «Sartre», Alférez, 22 (1948), pp.6-7.

AzCOAGA, Enrique, «La pobretería teatral y sus cómplices», Espectáculo (1951), 13.

—, «Las Misiones Pedagógicas», ROcc, 7-8 (1981), 222-232.

AZNAR SOlER, Manuel, «El Teatro Universitario en Barcelona durante el franquismo», en L. García Lorenzo, ed., 1999, pp.111-138.

AYllón, José, «Teatro de Cámara», Ínsula, 78 (15-VI-1952).

AzNAR Soler, Manuel, «Alfonso Sastre y José María de Quinto: breve historia de una lucha», Anthropos, 126 (1991), pp. 31-37.

- República literaria y revolución, Sevilla, Renacimiento, 2010.

—, «Arte nuevo (Un homenaje)», La Diabla. Revista Pedagógica del Teatro Español, 33 (2016), pp. 2-39.

- y Mancebo, María Fernanda, «El Búho, teatre de la FUE de la Universitat de València», en VV.AA., 1993, pp.9-22.

AzPILICUETA, Jaime, «El TEU de San Sebastián, antes y después (Pequeña historia de un grupo amateur donostiarra)», PA, 57 (1964), pp.57-59.

Bajo Martínez, María Jesús, «Orígenes del teatro universitario en Sevilla», Teatro (junio 1944), pp.45-49.

—, «La práctica escénica en la universidad española de posguerra: el TEU de Sevilla», Actas del I Congreso Iberoamericano de Teatro (Cádiz, Artes Gráficas Nuevas, 1996), pp.407-413.

—, «Tres décadas de teatro universitario en Sevilla», en García Lorenzo, ed., 1999, pp. 235-278.

-, El teatro universitario en Sevilla (1940-1970), tesis doctoral, Sevilla, Universidad de Sevilla, 2016.

- , y Romero Ferrer, Alberto, «La recuperación escénica de Valle-Inclán en el teatro andaluz (1954-2009)», Don Galán, 1 (2011).

BALTÉs, Blanca, Historia de la dirección escénica en España: Cayetano Luca de Tena, tesis doctoral, Universidad Complutense de Madrid, 2011.

BELLVER, Alejandro, «Un drama nuevo: TEU», BT, 521 (8-II-1948a).

—, «TEU: el afán y alegría del camino», BT, 387 (15-VIII-1948b).

-, «El TEU: qué es y qué representa en la escena barcelonesa», BT, 397 (23-IX-1948c).

Berghaus, Günter, ed. Fascism and Theater. Comparative Studies on the Aesthetics and Politics of Performance in Europe, 1925-1945, Providence / Oxford, Berghahn Books, 1996.

BONET, Laureano, La revista «Laye». Estudio y antología, Barcelona, Península, 1998.

BORRÁS, Tomás, «Movimiento teatral», CLC, 1/1 (1942). 
—, «Cómo debe ser el teatro falangista», Revista Nacional de Educación, 35 (XI-1943).

Bravo MARTínez, Francisco, Historia de la Falange Española de las JONS, Madrid, Afrodisio Aguado, 1940.

ByrD, Suzanne, La Barraca and the Spanish National Theatre, Nueva York, Abra Ediciones, 1975.

CALvo, Luis, «El TPU estrenó anoche el drama Tres ventanas, de Luis Delgado Benavente en el María Guerrero», ABC (23-IV-1953).

Campmany, Jaime, «El Festival Universitario de Cáceres», Arriba (9-VII-1955a).

—, «Ha comenzado el Festival de Teatro Universitario en Parma: gran éxito de La Celestina en el Teatro Regio de Parma», Arriba (26-IV-1955b).

CARBAJOSA, Mónica, La corte literaria de José Antonio: la primera generación cultural de la Falange, Barcelona, Crítica, 2003.

CARMONA VICTORIO, José, «Información y noticias teatrales: el TEU de la Escuela de Periodismo estrenó en el Teatro Beatriz varias obras», ABC (4-IV-1952).

[CASARES, Francisco], «Presentación del Teatro Nacional de la Falange. La verdad sospechosa, de Alarcón», LV (25-II-1939), p.12.

CAstilla, Alberto, «Diez años de Teatro Universitario en España y América (19581968)», en García Lorenzo, ed., 1999, pp.235-278.

CAUDET, Francisco, «La Hora (1948-1950) y la renovación del teatro español de posguerra», en Entre la cruz y la espada: en torno a la España de posguerra. Homenaje a Eugenio G. de Nora, ed. José Manuel López de Abiada (Madrid, Verbum, 1984), pp.109-126.

CAYUEla, Arturo M., Los autos sacramentales de Lope, reflejo de la cultura religiosa del poeta y de su tiempo, Madrid, Razón y Fe, 1935.

CERda MuÑoz, Alfredo, El teatro universitario en Guadalajara entre 1960 y 1990, Madrid, Mirada Malva, 2010.

Clavería, Alberto, «Teatro Nacional-Sindicalista. Actuación al aire libre de La Tarumba», Águilas, 199 (1937), p.6.

—, «Sobre una dramática futura. Guión para un ensayo», Haz (1-II-1944a), p.34

—, «Teatro escolar en España. El misterio español de Cristo. Una síntesis integral el drama religioso desde el siglo XII al XVII», LEL, 10 (1944b), p.10.

Clemente Balaguer, José-Carlos, «Renace el TEU de Barcelona», PA, 46 (1963).

Coll, Julio, «El Teatro de Estudio de Juan Germán Schroeder«, LEL, 22 (1945), p.10.

CORRALES EGEA, José, «Relaciones entre el auto sacramental y la Contrarreforma», Revista de Ideas Estéticas, 12 (1945), pp.511-514.

CORTEZO, Víctor María, «Plástica y ornamentación escénicas», RNE (1943), p.35.

CRUZ Hernández, Miguel, «Los autos sacramentales, ayer y hoy, en busca de su técnica», Teatro, 5 (1953), pp.45-46.

CuEVA, Jorge de la, «Teatro de la Falange: La cena del rey Baltasar», Ya (23-VII-1939).

Anales, 29-30 (2018), pp. 13-45 
—, «Inauguración del Teatro Nacional», Ya (27-IV-1940a).

—, «El otro. Drama de don Miguel de Unamuno», (1940b).

—, «Modesto Higueras, director del Teatro Español», Ya (28-X-1952).

CUEVA, José de la, «En el Retiro: Teatro Nacional de FET y de las JONS [La cena del rey Baltasar], Informaciones, 24 (1939).

Delgado, José Luis, «Martín Recuerda y el TEU de Granada», Granada hoy (30-V-2011).

DENNIS, Nigel, y Peral Vega, Emilio, ed. Teatro de la Guerra Civil: el bando nacional, Madrid, Fundamentos, 2010.

DíAZ HERNÁNDEZ, Onésimo, «Las revistas culturales en la España de la posguerra (1939-1951): una aproximación», Cuadernos del Instituto Antonio de Nebrija, 10 (2007), pp.201-224.

DíAZ PlajA, Fernando, La posguerra española en sus documentos, Barcelona, Plaza y Janés, 1970.

DíAZ PlajA, Guillermo, La voz iluminada: notas sobre el teatro a través de un cuarto de siglo, Barcelona, Instituto del Teatro Español, 1952.

DíAZ SANTILlanA, «Insuperable éxito del Teatro Popular Universitario con la Fedra de Séneca, en el Teatro Romano de Mérida», Hoy (10-XI-1953).

DíEz PuerTas, Emeterio, «El Teatro Nacional del Español: la crisis de marzo de 1942», RILCE, 29.2 (2013), pp.271-295.

DOMÉNECH, Ricardo, «Entrevista con Alfonso Sastre», en Alfonso Sastre, Teatro (Madrid, Taurus, 1964), 56-57.

Duende azul, El, «Teatro nuevo», Vértices (VI-1937).

E.A., «Novedades teatrales. ¿Quién mató al Comendador? El oro y el bosque. Teatro ambulante. Estrenados el 12 de octubre de 1944», Juventud, 55 (1944), p.8.

E.R.M., «Teatro universitario», Hoja oficial de la provincia de Barcelona (20-III1939), p. 7.

Entrambasaguas, Joaquín de, «Ante el tricentenario de Lope de Vega», Fénix, 1 (1935), pp.12-18.

- Lope de Vega, símbolo del temperamento estético español, Murcia, Universidad, 1936.

—, «Lope de Vega en la creación del Teatro Nacional», RNE, 35 (1943).

ESCOBAR, Luis, «La Tarumba. Teatro de la Falange», Y, 1 (1938), p.50.

—, «La dirección escénica de una obra teatral», RNE, 35 (1943).

-, En cuerpo y alma. Memorias, Madrid, Temas de Hoy, 2000.

FACIO, Ángel, ed., Alberto González Vergel. Trayectorias, Madrid, Teatro Español, 2008.

FERNÁNDEZ MARTÍNEZ, Pilar et alii, La Estafeta literaria y su contribución a la difusión de la cultura del siglo XX, Madrid, Sílex, 2010. 
FERnÁNDEZ Montesinos, Ángel, El teatro que he vivido. Memorias dialogadas de un director de escena, ed. A, Martínez Roger, Madrid, Publicaciones de la ADE, 2008.

Fernández Oliva, Antonio, José Luis López Vázquez. Un cómico dramático, Madrid, Editorial Difusión Cinematográfica Española, 1988.

FERNÁNDEZ TORRES, Alberto, ed., Documentos sobre el teatro independiente español, Madrid, CNNTE, 1987.

FERRÁn, Jaime, «Pasión de lo clásico en el teatro universitario», Alcalá, 70 (25-IV-1955).

FOGUET I BOREU, Francisco, «El teatro universitario en la Cataluña de la Segunda República (1935-19379», ALEC, 25 (2000), pp.821-888.

FOXÁ, Agustín de, «Segovia y su auto sacramental: El hospital de los locos», Vértice, 12 (1938), s.p.

FraGA, Jesús, «Teatros de cámara y teatro universitarios», CHA, 40 (1953), pp.106-107.

FrAILE, M. [1989], «Introducción», Teatro español en un acto (1940-1952), Madrid, Cátedra, pp. 9-31.

Frutos Cortés, Eugenio, ed. P. Calderón de la Barca, Autos sacramentales (Antología), Madrid, Editora Nacional, 1947.

—, «La voluntad y el libre albedrío en los autos sacramentales de Calderón», Revista de la Universidad de Zaragoza, 1 (1948), pp.3-26.

- La filosofía de Calderón en sus autos sacramentales, Zaragoza, Institución Fernando el Católico, 1952.

FUENTES SEGURA, M., «La escenografía en nuestra dramática», Haz, 22 (1945), pp.69-70.

GALLÉN, Enric, El teatre a la ciutat de Barcelona durante el règim franquista (19391954), Barcelona, Institut del Teatre, 1985.

GARBISU BuESA, Margarita: Índices de La Estafeta literaria (1994-2001). Contenidos literarios de la revista, Madrid, Fragua, 2004.

GARCíA GARZÓN, Juan Ignacio, 1985, «El director teatral Modesto Higueras falleció ayer en Madrid», ABC (11-X-1985).

GARCía LORENZO, Luciano, ed. Aproximación al teatro español universitario (TEU), Madrid, CSIC, 1999.

—, «Los autos sacramentales en España (1939-2000): recepción escénica y respuesta crítica», El teatro del Siglo de Oro ate los espacios de la crítica: encuentros y revisiones, ed. E. García Santo-Tomás (Madrid, Iberoamericana / Vervuert, 2002), pp.405-426.

-, y Muñoz Carabantes, Manuel, «El teatro de Calderón en la escena española (1939-1999)», en Calderón desde el 2000, ed. J. M. Díez Borque (Madrid, Ollero y Ramos, 2001), pp.419-433. 
GARCía NiETO, José, «Nuevos autores para un nuevo teatro», Juventud, 13 (1944), p.5.

GARCía Ruiz, Víctor, Víctor Ruiz Iriarte. Autor dramático, Madrid, Fundamentos, 1987.

- , «Un poco de ruido y no demasiadas nueces: los autos sacramentales en la España de Franco (1939-1975)», en Divinas y humanas letras. Doctrina y poesía en los autos sacramentales de Calderón, ed. Ignacio Arellano et alii (Pamplona, Universidad de Navarra, 1997), pp.119-166.

- «Calderón, Felipe Lluch y el auto sacramental en la España de los años 30», en Texto e imagen en Calderón, ed. M. Tietz (Stuttgart, Franz Steiner, 1998), pp.95-108.

- Continuidad y ruptura en el teatro español de la posguerra, Pamplona, EUNSA, 1999.

—, «Del gran teatro de España: un Calderón falangista», en Calderón 2000. Homenaje a Kurt Reichenberger en su 80 cumpleaños, ed. I. Arellano (Kassel, Reichenberger, 2002), pp.533-540.

-, Teatro y fascismo en España. El itinerario de Felipe Lluch, Madrid, Francfort, Iberoamericana / Vervuert, 2010.

-, y Torres Nebrera, Gregorio, dir., Historia y antología del teatro español de posguerra, I: 1940-1945, Madrid, Fundamentos, 2003.

-, y Torres Nebrera, Gregorio, dir., Historia y antología del teatro español de posguerra, II: 1945-1950, Madrid, Fundamentos, 2004.

GARCía SERRANO, Rafael, «Ficha de un escritor universitario», Haz, 4/16 (1944), p.51.

GIL Álvarez, Felipe, «Navidad en el teatro de Castilla», Haz, IV/9 (1943a), pp.24-25.

—, «Cien años de teatro en Rusia», Haz, IV/5 (1943b), pp.44-45, 60.

Gil FombellidA, María Carmen, Rivas Cherif, Margarita Xirgu y el teatro de la Segunda República, Madrid, Fundamentos, 2003.

Giménez Caballero, Ernesto, Arte y estado, Madrid, Gráfica Universal, 1935.

- Teatro escolar. Historia representable del drama religioso en España del siglo XII al siglo XVII. El misterio español de Cristo, Madrid, 1945.

Gómez DíAz, Luis Miguel, Teatro para una guerra (1936-1939). Textos y documentos, Madrid, Centro de Documentación Teatral, 2006.

Gómez García, Manuel, Modesto Higueras, un hombre de teatro: el maestro y la asamblea, Madrid, s.n., 2006.

GÓMEZ PICAZO, Elías, «María Guerrero: autores noveles presentados por el TEU de Periodismo», Madrid (9-IV-1954).

—, «Ciclo de conferencias sobre teatro español, por Modesto Higueras», Madrid (5-III-1960). 
—, «Sublime decisión, de Mihura, dirigida por Modesto Higueras», Madrid (28-V-1964).

GONZÁlez PAlENCIA, Ángel, «El arte de Calderón», RNE, 35 (1943).

GONZÁlEZ RuIZ, Nicolás, ed. Piezas maestras del teatro teológico español, Madrid, La Editorial Católica, 1946, 2 vols.

- La cultura española en los últimos veinte años: el teatro, Madrid, Imprenta Aguirre, 1949.

—, «El auto sacramental, martillo y espada», Teatro, 5 (1953a), pp.47-48.

—, «Una interesante sesión del Teatro Popular Universitario», Ya (24-XI-1953b).

—, «El auto sacramental, antecedentes del teatro de hoy», PA, 7 (1959), pp.8-9.

GonzÁlez Vergel, Alberto [2008], «Mirando hacia atrás... sin ira. Notas autobiográficas», en Facio, 2008, pp.15-30.

GORDÓN PASO, José, «El TEU y sus cinco años de labor», La Hora (26-XI-1950).

—, «Cincuenta años de teatro experimental en España», La Hora (24-VI-1950).

—, El teatro experimental, Madrid, Ediciones de Conferencias y Ensayos, 1959.

—, Teatro experimental español (Antología e historia), Madrid, Escelicer, 1965.

GRACIA, Jordi, «La estética social, Falange y el SEU», Cuadernos Hispanoamericanos, 561 (1997), pp. 75-95.

-, La resistencia silenciosa: fascismo y cultura en España, Barcelona, Anagrama, 2004.

- Estado y cultura: el despertar de una conciencia crítica bajo el franquismo, Barcelona, Anagrama, 2006.

GUIRAO GODíNEZ, Ginés, La vida cultural en una ciudad castellana de la retaguardia franquista: Ávila, tesis doctoral, Madrid, Universidad Complutense de Madrid, 2004.

HARO TECGLEN, Eduardo, «En el María Guerrero se estrenó El casamiento engañoso por el Teatro Universitario Español», Informaciones (13-X-1943).

Heras González, Juan Pablo, La labor teatral de Álvaro Custodio, tesis doctoral, Madrid, Universidad Complutense de Madrid, 2011.

HeRmAns Hub, «Avisos y leyendas en El casamiento engañoso de Gonzalo Torrente Ballester», Investigaciones semióticas. Actas del IV Simposio Internacional de la Asociación Española de Semiótica (Madrid, Visor, 1992), pp.649-661.

HeRnÁNDEZ SANDOICA, Elena, ed., Estudiantes contra Franco (1939-1975): oposición política y movilización juvenil, Madrid, La Esfera de los Libros, 2007.

Herrero, Vene, Historia de la dirección escénica en España: José Estruch, tesis doctoral, Universidad Complutense de Madrid, 2014.

Higueras de VAllejo, Juan J., «El Teatro Español Universitario (TEU): un lustro de sesenta y un años», s.a., www.rumbos.net/rastoria.

HiguERAS, Jacinto, Recuerdo del teatro universitario La Barraca, Granada, Fundación Caja de Granada, 1996.

Higueras, Modesto, «Teatros juveniles de propaganda», Haz (11-XI-1941), pp.10.

Anales, 29-30 (2018), pp. 13-45 
—, «La dirección artística y su realización», Espectáculo (VII / VIII-1944a), pp. 46-47.

—, «Lo espectacular en los teatros juveniles», Haz, IV/15 (1944), p.56.

—, «Lope el batihoja», Haz, IV/7 (1944c), p.38.

—, «¿Comediantes intuitivos o con formación?», Espectáculo (XI/XII-1945), pp. 27-28.

—, «Teatro Español Universitario», Guía (II-1948), pp. 24-25.

—, «Apuntes de un director», Aulas, 12 (1964), 12.

- El Teatro de Ensayo en España [mecanoscrito], Madrid, Fundación Juan March, 1965.

—, «Teatro de avanzada o de última hora», Los géneros teatrales en la escena española. Cinco conferencias en torno al día mundial del teatro, Madrid, Ministerio de Información y Turismo, 1977.

Hormigón, Juan Antonio [1971a], «Del teatro universitario a los teatros independientes», en Teatro, realismo y cultura de masas, Madrid, Cuadernos para el Diálogo, 1974, pp. 100-138.

- [1971B], «Del Mirlo Blanco a los teatros independientes», en Teatro, realismo y cultura de masas, Madrid, Cuadernos para el Diálogo, 1974, pp. 139-147.

—, «Años decisivos», en Rubio Jiménez, 2000a, pp. 249-305.

Huerta CALVO, Javier, «Análisis» en Clásicos entre siglos, número monográfico de Cuadernos de Teatro Clásico, 22 (2006).

—, «Clásicos cara al sol”, XXV Jornadas de Teatro del Siglo de Oro, Almería, Instituto de Estudios Almerienses, 2008.

- «Torrente Ballester: teoría teatral e ideario falangista», La Tabla redonda, 8 (2010), pp.77-91.

-, ed. La Barraca. Teatro y universidad, Ayer y hoy de una utopía, Madrid, Sociedad Estatal de Conmemoraciones Culturales, 2011

-, Javier, y Cienfuegos Antelo, Gema, El caballero de Olmedo. Versos y versiones, Olmedo, Festival de Olmedo / Universidad de Valladolid, 2013.

-, y Doménech Rico, Fernando, ed., La Barraca de García Lorca: entre el teatro y la utopía, Madrid, ITEM/Ediciones del Orto, 2012.

Interino, «El Teatro Universitario se presentó anoche en el Español con el estreno de una nueva versión de La estrella de Sevilla», ABC (8-III-1951).

JATO, David, «Bauticemos al comunismo», Haz, IV/12:12.

- La rebelión de los estudiantes. Apuntes para una historia del alegre SEU, Madrid, CIES, 1953.

José Luis, «El Teatro Universitario del SEU actuó en el Gran Teatro en obsequio de los combatientes heridos», Azul, 721 (29-I-1939), p.2.

LA RosA, Tristán, «Pedro Calderón de la Barca y Lope de Vega en Barcelona», LEL, 8 (1944), p.10. 
LABORDA, Ángel, «Labor del Teatro Nacional de Cámara y Ensayo, dirección de Modesto Higueras», Informaciones (28-III-1959).

LADRA, David, «Del teatro no profesional al teatro independiente bajo la Dictadura», PA, 352/1 (2017), pp.180-190.

LINARES, Francisco, «Theater and Falangism at the Beginning of the Franco Régime», en Berghaus, ed., 1996, pp.210-228.

LlORET MARTIN, Gonzalo, Tendencias renovadoras del teatro español del primer tercio del siglo XX: José Francés y Tomás Borrás, tesis doctoral, Sevilla, Universidad de Sevilla, 2015.

[LlOVET, Enrique], «El retablo del ángel, el hombre y la pastora, José García Nieto; Ático izquierda, Julio Angulo; Un día en la gloria, Víctor Ruiz Iriarte», Juventud, 61 (1944), p.8.

LluCH GARín, Felipe, «El teatro religioso de Lope de Vega», Ya (30-VIII-1935).

—, «El auto sacramental», RNE, 35 (2943), pp.7-17.

LOMA, José Antonio de la, «Seis meses de TEU», Estilo (15-VI-1948a).

—, «La próxima temporada artística del TEU», El Noticiero Universal (13-VIII-1948b).

-, «El TEU. Qué es y qué representa en la escena barcelonesa», BT, 397 (23-IX-1948c).

—, «Correo interior. La dirección del TEU y sus proyectos inmediatos», BT, 422 (17-III-1949a).

—, «¡A escena, el TEU!», Estilo (1949b).

LOPEZ GORGÉ, Jacinto, «Coloquio sobre el montaje de Yerma» [con la participación de Modesto Higueras], LEL, 1 (15-I-1972).

LÓPEZ SANCHO, Lorenzo, «Conferencias de Modesto Higueras en París», ABC (29-IV-1967).

LOzOYA, marqués de, «Menestralia», Azul, 460 (27-III-1938), p.1.

LUCA DE TENA, Cayetano, «Los autos sacramentales y el director de escena», Teatro, 5 (1953), pp.43-44.

MACHADO, Manuel, «Por el teatro de mañana», ABC -Sevilla- (28-I-1938a), p.3

—, «Por el teatro de mañana (II)», ABC -Sevilla- (19-II-1938b), p.3.

MAdRIGAl NeIRA, Marián, La memoria no es nostalgia: José Caballero, tesis doctoral, Madrid, Universidad Complutense de Madrid, 2001.

MAHANTA KÉBÉ, Serigne, Crítica teatral de posguerra en el periódico madrileño Arriba, tesis doctoral, Madrid, Universidad Complutense de Madrid, 2002.

MAInER, José-Carlos, Falange y literatura. Antología, Madrid, Labor, 1970.

MARAÑón MOYA, Gregorio, «Emilio Aladrén», Haz, IV/11 (1944), p.48.

MARQUERíE, Alfredo, «María Guerrero: presentación de la Compañía del Teatro Nacional [La cena del rey Baltasar]», Informaciones (29-IV-1940).

—, Desde la silla eléctrica: crítica teatral, Madrid, Editora Nacional, 1942a. 
—, «En los jardines del Retiro se representa un auto sacramental de Calderón: maravilloso espectáculo de arte que obtuvo un éxito inmenso [La cena del rey Baltasar]», Informaciones (3-VII-1942b).

-, En la jaula de los leones. Memorias y crítica, Madrid, Ediciones Españolas, $1944 a$.

-, «La cueva de Salamanca y La ciudad lejana de Alberto Crespo y Julián Ayesta», ABC (31-V-1944b), p.16.

—, Madrid hoy, Madrid, Tesoro, 1945.

—, «Dos importantes estrenos del TEU», ABC (30-XI-1947).

—, «Actuación del TEU en el Infanta Beatriz», ABC (16-IX-1949).

—, «En el Español el Teatro Popular Universitario estrenó La hidalga del valle, de Calderón», $A B C$ (26-V-1954).

—, «Curso de teatro de Modesto Higueras», ABC (25-II-1960).

—, XXV años de teatro en España, Madrid, Publicaciones Españolas, 1964.

—, Personas y personajes. Memorias informales, Barcelona, Dopesa, 1971.

MARTíNEZ CACHERO, José María, «Talía en la Guerra Civil: sobre el teatro de la zona nacional», en El canto de las sirenas (Páginas de investigación y crítica (Oviedo, Universidad de Oviedo, 2000), pp.295-318.

Martínez-Michel, Paula, Censura y represión intelectual en la España franquista: el caso de Alfonso Sastre, Fuenterrabía, Hiru, 2003.

MCCARTHY, Jim, Political Theatre during the Spanish Civil War, Cardiff, University of Wales Press, 1998.

MELCHOR, Federico, «Sobre la situación de la juventud en el régimen franquista», Nuestra bandera, 1-2 (1941), pp.41-49.

Mermall, Thomas, «Aesthetics and Politics in Falangist Culture (1935-45)», BHS, 50.1 (1973), pp. 45-55.

Miner OtAmendi, José Manuel, «Teatro: el crítico escribe [El hospital de los locos], El Alcázar (10-IV-1952).

MolinARI, Andrés, La Universidad de Granada y el teatro, Granada, Editorial de la Universidad de Granada, 2006.

MONTES AGUDO, Gumersindo, «Ars et Fascis. Retorno a lo mejor de nuestro arte», Heraldo de Zamora (10-XI-1937).

Moreno, José, «En busca de un teatro: 4 preguntas a Modesto Higueras», PA, 118 (1970), p.111.

MUNDi PEDRET, Francisco, El teatro de la guerra civil, Barcelona, PPU.

MuÑoz CÁlIz, Berta, El teatro crítico español durante el franquismo, visto por sus censores, Madrid, Fundación Universitaria Española, 2005.

MuÑoz CARABantes, Manuel, «Aproximación al TEU», Ínsula, 654 (2001), pp. 20-22.

NAVARro, Mario, «Misión del TEU», Cátedra, 3 (II-1943), p.2. 
—, «Nuevas orientaciones del TEU. La visita del camarada González Robles», Cátedra, 10 (IV-1945).

Nieto GARCíA, María Dolores, «Aportación de La Estafeta literaria en su primera etapa (1944-1946), al estudio de la poesía y del teatro en la España de la posguerra», en VVAA.: La Estafeta literaria y su contribución a la difusión de la cultura del siglo xx (Madrid, Sílex, 2010), pp.103-128.

Obregón, Antonio de, «Crónica de teatro. El público», Arriba (30-V-1939a).

—, «Hacia una censura estética», Arriba (12-V-1939b).

—, «El teatro, en pie», Arriba (4-III-1939c).

—, «El teatro de las Organizaciones Juveniles», Arriba (13-VII-1939d).

Olano, Antonio D., «Una gran labor (popular) del Frente de Juventudes: el TEU representa teatro al aire libre y para todo el público», El Alcázar (21-VI-1953a).

—, «Más sobre los teatros de cámara y su dirección: hoy hablan del tema Modesto Higueras y José Antonio Medrano», El Alcázar (31-XII-1953b).

—, «Los próximos proyectos del Teatro Español, explicados por su director Modesto Higueras», El Alcázar (11-XI-1953).

Oliva, César, Ocho años de teatro universitario, Murcia, Universidad de Murcia, 1975.

—, ed., Los papeles del Seminario «Teatro y Universidad», Madrid, Centro de Documentación Teatral, 1980.

—, El teatro desde 1936, Madrid, Alhambra, 1989.

- [1999], «La escena universitaria española», en García Lorenzo, ed., 1999, pp.15-30.

PACo, Mariano de, «Alfonso Sastre y Arte Nuevo», Cuadernos El Público, 38 (1988), pp. 29-37.

- «Ángel Valbuena y el auto sacramental en el teatro español del siglo XX», Monteagudo, 5 (2000a), pp.97-112.

—, «Autos sacramentales contemporáneos», Cuadernos del Lazarillo, 18 (2000b), pp.30-35.

-, «El auto sacramental en el siglo xx: variaciones escénicas del modelo calderoniano», en Calderón: sistema dramático y técnicas escénicas. Actas de las XXIII Jornadas de Teatro Clásico, ed. F. Pedraza et alii (Almagro, Universidad de Castilla-La Mancha, 2000c), pp.365-388.

—, «El auto sacramental en el teatro español contemporáneo (1940-1997)», en Homenaje a José María Martínez Cachero (Oviedo, Universidad de Oviedo, 2000d), III, pp.295-309.

PAyÁ Beltrán, José, Alfonso Paso y el teatro español durante el franquismo, tesis doctoral, Alicante, Universidad de Alicante, 2015.

Peláez, A., ed., Historia de los Teatros Nacionales (1939-1962), Centro de Documentación Teatral, Ministerio de Cultura, Madrid, 1993, vol. 1. 
PÉREZ ABAD, Nieves, Formación teatral y universidad: historia del teatro universitario de Murcia (1935-1984), tesis doctoral, Murcia, Universidad de Murcia, 2017.

PÉREZ BOWIE, José Antonio, «El TEU salmantino: treinta años de actividad teatral universitaria (1940-1969)», en García Lorenzo, ed., 1999, pp.139-172.

—, «Estudio preliminar: Gonzalo Torrente Ballester, teórico y crítico del teatro», en Torrente Ballester, 2009, pp.13-73.

PÉRez de Olaguer, Gonzalo, «Teatro y universidad: del compromiso al olvido», en García Lorenzo, ed., 1999, pp.55-62.

PÉREZ-RASILLA, Eduardo, «La situación del teatro universitario en España desde 1939 a 1967», en García Lorenzo, ed., 1999, pp.31-54.

Pick, «En el Beatriz se celebró anoche el homenaje a Modesto Higueras, que va a dirigir el Teatro Nacional de Santo Domingo», ABC (28-XII-1951).

Pinilla de las Heras, Esteban, En manos de la libertad. Dimensiones políticas del grupo «Laye» en Barcelona, Barcelona, Anthropos, 1989.

Plaza Chillón, José Luis, Clasicismo y vanguardia en La Barraca de Federico García Lorca: de pintura y teatro, Granada, Comares, 2001.

PRENDES GUARDIOLA, Manuel, «Tradición y vanguardia en El viaje del joven Tobías de Torrente Ballester», RILCE, 22.2 (2006), pp.223-236.

Quinto, José María, «Coincidencia del TAS con la Falange de 1935», La Hora, 64 (8-X-1950).

-, «Breve historia de una lucha», en A. Sastre, Cargamento de sueños. Prólogo patético. Asalto nocturno, Madrid, Taurus, 1964, pp. 48-55.

- «Sobre el verdadero estreno en España de La casa de Bernarda Alba», Ínsula, 476-477 (1986), p. 8.

—, «Memoria personal sobre el teatro», en L. García Lorenzo, ed., Aproximación al teatro español universitario (TEU), Madrid, CSIC, 1999, pp. 63-110.

RIDRUEJO, Dionisio, Casi unas memorias: con fuego y con raíces, Barcelona, Planeta, 1976.

Ríos CARRATALÁ, Juan A., «[Introducción]» a V. Ruiz Iriarte, Un día en la gloria, Alicante, Biblioteca Virtual Miguel de Cervantes, 2009. http://www.cervantesvirtual.com/obra-visor/un-dia-en-la-gloria-farsa-en-un-acto--0/html/ p0000001.htm\#I_0_

-, A la sombra de Lorca y Buñuel: Eduardo Ugarte, Alicante, Universidad de Alicante, 1995.

RÓDENAS, Miguel, «Español: Las mocedades del Cid», ABC (2-I-1941), p.7.

- , «Notas teatrales: anoche el TEU representó en el María Guerrero La guarda cuidadosa y El hijo pródigo», ABC (7-VII-1942a).

- , «Alto y profundo espectáculo de arte [El pleito matrimonial del alma y el cuerpo]», ABC (3-VII-1942b).

—, «Representación extraordinaria del TEU, en el Español», ABC (9-VI-1943a).

—, «Estreno en el María Guerrero de El casamiento engañoso», ABC (13-X-1943b).

Anales, 29-30 (2018), pp. 13-45 
RODRÍGUEZ DE LEÓn, Antonio, «En el María Guerrero se dio a conocer Escuadra hacia la muerte, en función única y como iniciación del ciclo de teatro universitario», ABC (19-III-1953).

RodríGUEZ-SOlÁs, David, Teatros nacionales republicanos. La Segunda República y el teatro clásico español, Madrid / Fráncfort, Iberoamericana / Vervuert, 2014.

—, «La Barraca, 1933: el giro lopiano de García Lorca», Anuario Lope de Vega, 22 (2016), pp. 200-216.

Ros, Samuel, «Un auto de Calderón en los jardines del Retiro en el año de la victoria», Vértice, 25 (1939), s.p.

Rubio JimÉnEZ, Jesús, ed., Teatro universitario en Zaragoza: 1939-1999, Zaragoza, Prensas Universitarias de Zaragoza, 2000a.

- y AlmárCegui, Patricia, «El teatro universitario en Zaragoza (1955-1965), en Rubio Jiménez, ed., 2000a, pp.43-123.

RUIZ CARNICER, Miguel Ángel, «Estética falangista y penetración de las vanguardias artísticas: Proa, revista del SEU de Zaragoza (1940-1958)», Boletín del Museo e Instituto Camón Aznar, XXXIV (1988), pp.173-199.

-, El SEU (1939-1965). La socialización política de la juventud universitaria en el franquismo, Madrid, Siglo XXI, 1996a.

—, «La voz de la juventud. Prensa universitaria del SEU en el franquismo», BHi, 98/1 (1996b), pp.175-199.

—, «De la agitación fascista al compromiso social. Contexto histórico y trayectoria del TEU del distrito de Zaragoza», en Rubio Jiménez, ed., 2000a, pp. 15-42.

RUIz IRIARTE, Víctor, «Un día en la gloria», Haz, IV/1 (1943a), s.p.

—, «Crónica de un mes de estreno», Haz, IV/2 (1943b), p. 46.

—, «Crónica de un mes de estreno», Haz, IV/5 (1943c), p.47.

—, «Fuenteovejuna», LEL, 2 (1944a), p.10.

—, «La plástica en nuestros escenarios», LEL, 17 (1944b), p.10.

—, «La vida es sueño en Barcelona... y en Granada», LEL, 8 (1944c), p.28.

- «Teatro juveniles. Los directores del TEU y del Lope de Rueda fijan su postura en nuestra actualidad teatral», LEL, 9 (1944d), p.10.

—, «Un teatro de cámara», LEL, 7 (1944e), p.11.

-, «Monólogo ante la batería» [Sobre El celoso por infiel, de Eusebio García Luengo, y sobre Retablo del Ángel, el Hombre y la Pastora, de José García Nieto], LEL, $24\left(1945^{\mathrm{a}}\right), \mathrm{p} .10$.

- «Hacia un nuevo teatro religioso. Manifestaciones de don Manuel Herrera Oria», LEL, 39 (1945b), p.10.

Ruiz VAlderRama, «Actuación del TEU de Salamanca en el teatro Avenida», Diario de Burgos (12-XII-1946).

SÁenz de la Calzada, Luis, La Barraca, Teatro Universitario, Madrid, Revista de Occidente, 1976. 
SÁEZ MARÍN, Juan, El Frente de Juventudes: política y juventud en la España de la posguerra (1937-1970), Madrid, Siglo XXI, 1988.

SAINZ DE LA MAZA, Regino, «Demostración nacional en el Español», ABC (1-X1943), p. 27.

SAlgueiro, Roberto, «La práctica escénica en la Universidad de Santiago de Compostela entre los años 1936 y 1975», en García Lorenzo, ed., 1999, pp.173-224.

SÁNCHEZ DEL ARCO, Manuel, «Versos en la Alcazaba y trabajo en el marr», $A B C$ (24-VIII-1951), p.15.

SÁNCHEZ CAMARGO, Manuel, «Teatro: gran gala espectacular en el Retiro [EL pleito matrimonial del alma y el cuerpo]», El Alcázar (3-VII-1942).

—, «Teatro: El casamiento engañoso», El Alcázar (13-X-1943a).

-, «Teatro: El pleito matrimonial entre el alma y el cuerpo y la Mojiganga de la muerte», El Alcázar (18-III-1943b).

SÁnCHEZ FERlosio, Rafael, «Demasiada perfección en Alcalá», Alcalá, 4 (10-III1952), p.5.

SÁNCHEZ MAZAS, Rafael, «Lo universitario y lo popular», Haz, 2 (1935), p.3.

SANVISENS I MARFUlL, Alexandre, ed. Autos sacramentales eucarísticos, pról. de José María Castro y Calvo, Barcelona, Cervantes, 1952.

SASTRE, Alfonso, «Tirso de Molina en el teatro María Guerrero», LH, 4 (6-XI-1948), p.20.

—, «El teatro nacional», LH, 22 (1-IV-1949a), p.11.

—, «El teatro y la universidad», LH, 25 (22-VI-1949b), p.11.

—, «El teatro de títeres», LH, 40 (4-XII-1949c), s.p.

—, «Teatro y política», LH, 43 (22-I-1950a), s.p.

—, «Tirso de Molina en Roma», LH (VIII-1950b), s.p.

—, «Hacia una enseñanza universitaria del teatro», LH, 71 (1950c), s.p.

—, «Arte nuevo», LH, 43 (22-I-1950d), s.p.

—, «La universidad y el teatro», Guía (V-1951), p.31.

—, «Nueva salida del Teatro Popular Universitario», Correo literario, 71 (15-V1953), p.10.

—, «Carta abierta a Modesto Higueras», Informaciones (13-XI-1954).

SCHROEDER, Juan Germán, «20 años de teatro no profesional», PA, 45 (1953).

[Secretario Provincial del SEU de Zamora], «Glosas de nuestros postulados», Imperio. Diario de Zamora de Falange Española de las JONS, 65 (16-I-1937), p.3.

Sijé, Ramón, «El comulgatorio espiritual (Hacia una definición del auto sacramental)», en Miguel Hernández, ed. María de Gracia Ifach (Madrid, Taurus, 1934), pp.302-305.

SIRERA, Josep Lluís, «El teatre universitari a la inmediata post-guerra», en VV.AA., 1993, pp.23-34. 
STURN, Suzanne, «Federico García Lorca's 1932 Production of La vida es sueño», Theatre History Studies, 12 (1992), pp. 89-105.

[Subdelegado Prensa y Propaganda del SEU de Soria]: «Teatro Español Universitario», Labor (5-III-1940), p.3.

SuElto de SÁENZ, P.G., «El teatro universitario español en los últimos treinta años», Thesaurus, 19 (1964), pp.543-557.

TAMAYO, José, «El teatro popular español visto por un director», Teatro, 5 (1953a), pp.33-38.

—, «Un auto sacramental en el Vaticano», Teatro, 5 (1953b), pp.58-64.

TEBAR, Juan, «Necesidad de un teatro nuevo», Haz (16-X-1939), pp.30-31.

TERrYN, Nathalie, «José Ricardo Morales et El Búho, théâtre universitaire de la Federación Universitaria Escolar (FUE) de Valence», Cauces, 2 (2001), pp.257-272.

Thomas, Joaquín E., «Siguiendo al carro de Tespis. El teatro del pueblo en Portugal», Haz, IV/15 (1944) p.55.

TORRAlBa Soriano, Federico, Notas para la creación de un Teatro Nacional Español, Zaragoza, Tipografía E. Bendejo, 1937.

TORRente BALlester, Gonzalo [1937], Razón y ser de la dramática futura, en Torrente Ballester, 2009, pp.79-86.

- [1941A], «Epístola al poeta Machado sobre la función de la crítica teatral», en Torrente Ballester, 2009, pp. 98-100.

— [1941B], «El problema de la forma dramática», en Torrente Ballester, 2009, pp.79-91.

- [1941C], «Cincuenta años de teatro español y algunas cosas más», en Torrente Ballester, 2009, pp.124-137.

- [1949], «Crónica de teatros», en Torrente Ballester, 2009, pp. 147-149.

- [1950], «Crónica de teatros», en Torrente Ballester, 2009, pp. 169-172.

—, «El Teatro Popular Universitario estrena Fedra de Séneca», Arriba (24-X-1953).

- Escritos de teoría y crítica teatral, ed. José Antonio Pérez Bowie, Vigo, Academia del Hispanismo, 2009.

Ullán, José Miguel, «El TEU o la desolación de la quimera», PA, 52 (1964), pp.42-43.

VALEMBOIS, Víctor, «El teatro de cámara en la posguerra española», Segismundo (1976), 13-24.

VAlero López, José, «Modesto Higueras Cátedra, actor de La Barraca, añora en extremo a Lorca», Jaén (22-IX-1985).

VALLÉs BELENGUER, José, «El teatro estudiantil en Huesca a mediados del siglo xx», Diario del Alto Aragón (10-VIII-2009).

VizCAÍNO CASAS, Fernando, La España de posguerra, 1939-1953, Barcelona, Planeta, 1975. 
VV.AA., La revolución nacional desde la universidad, Madrid, Jefatura Provincial de FET y de las JONS, 1939.

VV.AA., Teatro de escuadra. Obras seleccionadas, Almería, s.n., 1953.

VV.AA., XXV años de teatro en España, Madrid, Publicaciones Españolas, 1964.

VV.AA., 60 anys de teatre universitari, Valencia, Universitat de València, 1993.

VV.AA., Miguel Prieto (1907-1956): la armonía y la furia, Madrid, Sociedad Estatal de Conmemoraciones Culturales, 2007.

WAHNón, Sultana, «The Theatre Aesthetics of the Falange», en Berghaus, ed., 1996, pp.191-209.

YAMAGUCHI, Hajime, «Torrente y su teatro», Gonzalo Torrente Ballester, ed. José Paulino y Carmen Becerra (Madrid, Editorial Complutense, 2001), pp.149-161. ZÚÑIGA, Ángel, «Moratín», LVE (2-VII-1948), p.7. 